\title{
A comparison study of the characteristics of pauses and breath groups during paragraph reading for normal female adults with and without voice disorders
}

\author{
Hwa Young Pyo* \\ Department of Speech and Language Pathology, Chosun University, Gwangju, Korea
}

\begin{abstract}
This study was conducted to identify the characteristics of pauses and breath groups made by normal adults and patients with voice disorders while reading a paragraph. Forty normal female adults and forty female patients with a functional voice disorder (18-45 yrs.) read the "Gaeul" paragraph with the "Running Speech" protocol of the Phonatory Aerodynamic System (PAS), by which the pauses with or without inspiration and between or within syntactic words and breath groups were analyzed. The number of pauses with inspiration was found to be higher in the patient group, but the number of pauses without inspiration was higher in the normal group. The rate of syntactic word boundaries with pauses with inspiration was higher in the patient group, while the number of syllables per breath group was higher in the normal group. As these results can be explained by patients' poor breath support due to glottal insufficiency, the question of whether voice disorder patients use their pauses and breath groups properly should be considered carefully in evaluation and intervention.
\end{abstract}

Keywords: voice disorder, aerodynamic analysis, pause, breath group

\section{1. 서론}

호흡단락(breath group)은 한 번의 호흡 동안 산출되는 일련의 음절 혹은 단어군을 의미한다(Wang et al., 2012). 호흡단락은 휴 지(pause)를 통해 구분이 되는데 성공적인 의사소통을 위해서는 통사적으로 중요한 경계에서 휴지를 사용해야 하며 청자들은 휴지를 통해 통사적, 의미적 단위를 구분하게 된다(Huber et al., 2012). Huber et al.(2012)은 문법적으로 복잡한 문장을 이해하는
데 음도의 변화곡선(pitch contour)보다 휴지가 더 중요하게 사 용된다고 하여 의사소통에 있어 휴지의 중요성을 강조하였다.

휴지는 발화과제나 발화길이, 발화속도에 따라서 달라진다. Yoo \& Shin(2019)은 일반성인을 대상으로 자유발화와 낭독발 화를 비교한 결과 낭독발화에서 더 짧은 휴지를 사용하는 것으 로 보고하였다. Malecot et al.(1972)은 짧은 문장에 비해 긴 문장 에서 상대적으로 쉼 길이가 짧아진다고 하였다(as cited in Ko et al., 2010). Lee \& $\operatorname{Kim}(2017)$ 은 일반아동과 말소리장애 아동을

* entvoice@chosun.ac.kr, Corresponding author

Received 19 November 2019; Revised 30 November 2019; Accepted 2 December 2019

(C) Copyright 2019 Korean Society of Speech Sciences. This is an Open-Access article distributed under the terms of the Creative Commons Attribution NonCommercial License (http://creativecommons.org/licenses/by-nc/4.0) which permits unrestricted non-commercial use, distribution, and reproduction in any medium, provided the original work is properly cited. 
대상으로 발화속도와 쉼의 길이 및 빈도를 비교한 결과 발화속 도가 빠를수록 쉼의 길이와 빈도는 낮게 나타난다고 보고하였다.

휴지는 대화상황이나 대화 상대에 따라서도 달라질 수 있다. Yoo \& Shin(2019)은 자유발화는 즉각적인 발화계획이 필요하 므로 낭독발화보다 인지적 부담이 크기 때문에 휴지가 더 길어 진다고 하였다. 이에 비추어 보면 조용한 상황, 친숙한 상황, 친 숙한 상대와의 대화는 시끄러운 상황, 말하기 부담스러운 상황, 친숙하지 않은 상대와의 대화보다 더 짧은 휴지를 보일 수 있다. 또한 대화상대자가 의사소통 문제나 청각 문제를 동반하고 있 다면 정상 화자와 대화할 때와는 더 느린 발화속도와 더 긴 휴 지를 동반하게 될 것이다.

이와 같이 휴지는 원활한 의사소통에 있어 중요한 역할을 하 기 때문에 의사소통 문제가 있는 화자의 휴지 특성에 대한 연구 도 꾸준히 이루어지고 있다. Choi(2001)는 청각장애 아동을 대 상으로 어절간, 어절내 쉼의 빈도를 비교한 결과 청각장애 아동 은 건청 아동에 비해 어절간 및 어절내 쉼의 빈도가 유의하게 높게 나타났다고 했다. Lee et al.(2007)은 뇌성마비 아동을 대상 으로 쉼의 빈도와 길이를 측정하여 명료도가 낮은 뇌성마비 아 동이 보인 쉼의 빈도가 정상 아동보다 더 높았고 쉼의 길이도 더 길었다고 보고하였다.

휴지에 의해 구분되는 단락을 의미단락이라고 부르기도 하 지만 호흡단락이라고도 부르는 이유는 휴지를 통해 발화를 지 속할 수 있는 흡기류를 확보하기 때문이다. 성대질환을 동반하 는 음성장애 화자들은 성대 폐쇄부전을 동반하는 경우가 많고 이로 인해 발화 시 호흡조절이 용이하지 않다. 이러한 측면에서 음성장애 화자의 휴지 및 호흡단락 특성은 다른 의사소통장애 화자와 또 다른 양상을 보일 수 있다. 그러나 음성장애 화자의 휴지에 대한 연구는 매우 부족하다. Ko et al.(2010)이 파킨슨 병 환자의 쉼 특성을 정상 화자와 비교하여 보고하였으나 이들은 신경학적 문제를 동반하고 있어 일반 음성장애 화자에게 이 결 과를 적용하기는 무리가 있다. Pyo et al.(2014)이 정상 화자와 성 대 양성병변을 동반한 음성장애 화자의 호흡단락을 비교한 결 과를 보고하였으나 이는 예비연구로서 그 대상자 수가 부족하 여 결과의 일반화에 무리가 있다.

이에 본 연구는 정상 성인 화자와 음성장애 성인 화자의 휴지 특성을 공기역학적 평가기기를 이용하여 측정해보고자 한다. 두 집단 간의 휴지 특성을 비교함으로써 정상군과 음성장애 화 자군의 특성을 파악하고 이를 통해 음성장애 화자의 평가 및 중 재 시 어떠한 점을 고려해야 하는지 숙고해보고자 한다.

\section{2. 연구방법}

본 연구는 조선대학교 생명윤리위원회의 승인을 받고 시행 되었다(IRB No.: 2-1041055-AB-N-01-2019-21).

\section{1. 연구 참여자}

본 연구의 참여자는 18 45세의 여성 성인 화자로서 정상 성 대를 가지고 있는 것으로 판단되는 정상 성인 화자 40 명과 기능
적 음성장애를 동반한 음성장애 성인 화자 40 명을 대상으로 하 였다. 휴지가 성별에 따라 유의한 결과를 보였다는 Yoo \& Shin(2019)의 연구결과에 따라 여성 참여자로 한정하였다.

정상 성인 여성 화자군(이하, 정상군) 40 명은 본인이 음성문 제가 없다고 보고하였고 음성장애의 평가 및 연구경력이 10 년 이상인 음성장애 전문가 2 인이 GRBAS 척도평정을 실시한 결 과 모두 $\mathrm{G}$ 척도 점수로 0 점(정상)을 부여한 참여자들이다. 이들 은 실험 당시 음성문제는 물론, 호흡기 질환, 청각 문제, 알레르 기성 비염 등 성대 및 음성산출에 영향을 미칠 만한 질환을 동 반하지 않았고 고혈압 약, 항역류성 약물 등 음성산출에 영향을 미칠 만한 약물을 복용하지 않는 것으로 보고되었다. 또한 음성 문제를 포함하여 말소리, 유창성 등 의사소통의 문제를 동반하 지 않는 것으로 나타났다. 이들의 평균연령은 29.8세(표준편차 7.65)이고 연령범위는 18 42세였다.

음성장애 성인 여성 화자군(이하, 환자군) 40 명은 이비인후 과 두경부 전문의가 기능적 음성장애를 동반하고 있는 것으로 진단한 환자들이었다. 이들은 성대질환 외의 다른 질환을 동반 하지 않았고 진단 후 수술이나 약물 처치 혹은 음성치료를 받지 않은 것으로 보고되었다. 정상군과 마찬가지로 음성 문제 외의 의사소통 문제는 동반하고 있지 않은 것으로 판단되었다. 평균 연령은 33.4세(표준편차 8.23)이고 연령범위는 19 47세였다. 두 군의 연령차는 $t$ 검정 결과 유의한 차이가 없는 것으로 나타났 다( $p>.05)$. 이들이 동반한 성대질환은 성대용종(vocal polyp; 16 명), 성대결절(vocal nodules; 14명), 만성후두염(chronic laryngitis; 7 명), 성대결절 및 성대용종(2명), 근긴장성 발성장애(muscle tension dysphonia, MTD; 1명)였다. 앞서 정상 음성 여부를 판정 한 음성장애 전문가 2 인이 $\mathrm{GRBAS}$ 척도 중 $\mathrm{G}$ 척도 평정을 통해 중증도를 판정하였는데 환자군의 평균 $\mathrm{G}$ 척도의 점수는 1.88 점 (표준편차 0.69점)이었다.

\section{2. 실험방법}

\subsection{1. 사용 기기}

본 연구에서 사용한 기기는 Phonatory Aerodynamic System (PAS, Model No. 6600, PENTAX Medical Co., New Jersey, USA) 의 프로토콜 중 하나인 Running Speech이다. 이는 문단낭독 시 발화에 동반되는 호기 및 흡기의 기류량, 기류체적 및 지속시간 의 측정치를 제공한다.

\subsection{2. 사용 발화자료}

본 연구의 참여자들은 Running Speech 검사 시 '가을(Kim, 2005)' 문단 중 일부로 210 음절로 구성되어있으며 낭독 시 대략 45초 안팎의 시간이 소요된다. '가을' 문단 전체를 낭독하면 대략 1 분 안팎의 시간이 소요되는데 그 일부를 발화자료로 선택한 것은 Han et al.(2008)이 정상화자를 대상으로 Running Speech 검사를 시행할 때 마스크를 착용한 상태에서 60 초 동안 발화를 하는 것 이 평소 발화 상태보다 더 힘들었다고 보고한 내용을 참고하였 다. 그 발화자료는 표 1 에 제시하였다. 
표 1. 발화 문단 내용

Table 1. Content of reading material

우리나라의 가을은 참으로 아름답다. 무엇보다도 산에 오를 땐 더욱 더 그 빼어난 아름다움이 느껴진다. 쓰다듬어진 듯한 완만 함과 깎아놓은 듯한 뾰족함이 어우러진 산등성이를 따라 오르다 보면 절로 감탄을 금할 수가 없게 된다. 붉은색, 푸른색, 노란색 등의 여러 가지 색깔이 어우러져 타는 듯한 감동을 주며 나아가 신비롭기까지 하다. 솦속에 누워서 하늘을 바라보라. 쌍쌍이 짝 지어있는 듯한 흰 구름, 높고 파란 하늘을 쳐다보고 있노라면 과 연 옛부터 가을을 천고마비의 계절이라 일컫는 이유를 알게 될 것만 같다.

\subsection{3. 실험 절차}

발화자료는 A4 용지에 글자크기 20, 줄간격 280으로 하여 인 쇄한 후 코팅하여 참여자에게 제시하였다. 참여자로 하여금 시 작 전에 발화자료를 눈으로 한 번 읽어 익숙하게 하였다. 검사 자가 눈높이에 발화자료를 제시해준 후 낭독을 시작하도록 하 면 참여자는 PAS의 기류측정용 마스크를 얼굴에 밀착시킨 후 평상시의 음도와 강도로 편안하게 문단을 읽도록 하였다. 1 회 낭독 후 낭독 시 실수가 3 회 이상 나타날 경우 다시 한 번 읽도 록 하였다.

\section{3. 분석방법}

\subsection{1. 발화자료 분석}

Running Speech를 통해 발화자료를 낭독하면 그림 1과 같은 화면을 얻을 수 있다.

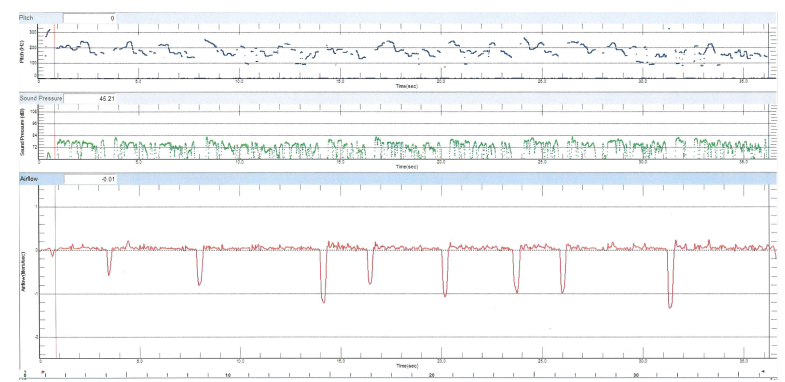

그림 1. Running speech를 이용한 문단낭독 후 화면

Figure 1. Screen display of running speech protocol after paragraph reading

그림에서 보는 바와 같이 문단낭독 화면은 세 개의 창 (window)으로 나뉘어 제시되는데 첫 번째 창은 음도(pitch), 두 번째 창은 강도(sound pressure), 세 번째 창은 기량(airflow)을 나 타낸다.

Yoo \& Shin(2019)은 휴지가 발화말에서 이루어졌는가, 발화 내에서 이루어졌는가와 들숨을 동반하는가, 하지 않는가에 따 라 휴지의 유형을 네 가지로 나누었다. 본 연구는 이 분류유형 을 따르되 발화 대신 어절을 구분 기준으로 하였다. 어절의 구 분은 $\operatorname{Kim}(2002)$ 에 따라 띄어쓰기를 기준으로 구분하였다. 이는
Winkworth et al.(1994)이 발화 시 호흡경계는 문법구조와 같이 구둣점이나 언어적 요소에 의해 판단하는 것이 논리적이라고 한 것과도 일치한다. 어절 경계는 본 연구자와, 아동언어발달장 애 전문가로서 언어병리학 박사학위 소지자 2 인의 전문가와 협 의하여 확정하였다. 이를 통해 확정된 전체 어절의 수는 69 개였다.

어절과 어절 사이에서 나타난 휴지를 어절간 휴지로 하고, 한 어절이 끝나기 전에 나타난 휴지를 어절내 휴지로 하여 그 횟수 를 측정하였다. Running Speech의 화면을 기준으로 어절간 혹은 어절내 휴지 시 기류량이 0 인 선 아래로 내려가 흡기가 일어났 음을 보여주는 하강곡선이 나타나면 흡기를 동반하는 것으로 하였다. 이에 따라 흡기 동반 어절간 휴지, 흡기 미동반 어절간 휴지, 흡기 동반 어절내 휴지, 흡기 미동반 어절내 휴지로 휴지 의 유형을 나누었다.

선행연구에서는 휴지가 일어난 것으로 간주하는 휴지 길이 는 0.1 초부터 0.25 초까지 다양하게 설정하고 있다(Ko et al., 2010; Lee \& Kim, 2017; Yoo \& Shin, 2019). 본 연구는 0.2초 이상 유지되는 경우를 휴지로 설정하였다.

그림 2는 휴지 유형 중 흡기 동반 어절간 휴지, 흡기 미동반 어절간 휴지와 흡기 미동반 어절내 휴지의 예를 보여준다.

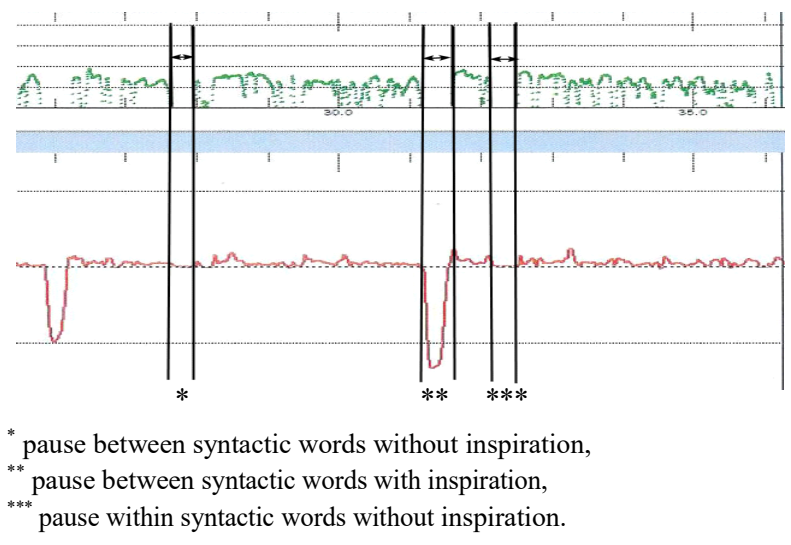

그림 2. 흡기 동반 및 미동반 어절간 휴지와 흡기 미동반 어절내 휴지의 예

Figure 2. Examples of pauses between syntactic words with and without inspiration and pause within syntactic words without inspiration

그림에서 화살표로 표시된 구간 중 첫 번째 구간은 ‘쌍쌍이 짝지어있는 듯한’에서 ‘짝지어있는'과 ‘듯한' 사이의 휴지를 나 타낸다. 발화의 강도를 표시하는 위쪽 창에는 0.24 초의 발화공 백이 있으나 기류량을 표시하는 아래쪽 창에는 흡기의 표시가 없어 이는 흡기 미동반 어절간 휴지에 해당된다. 두 번째 구간 은 ‘높고 파란 하늘을 쳐다보고 있노라면'에서 ‘있노라면' 다음 의 휴지를 나타낸다. 이 경우는 아래쪽 창에 흡기 표시가 나타 나므로 흡기 동반 어절간 휴지에 해당된다. 세 번째 구간은 ‘옛 부터'에서 ‘옛'과 ‘부터' 사이에서 0.26 초간 나타나 어절내에서 이루어진 휴지인데 흡기를 동반하고 있지 않으므로 흡기 미동 반 어절내 휴지에 해당된다.

호흡단락수는 전체 흡기횟수에서 1 을 더해서 구하였다. 예를 들어 전체 흡기횟수가 10 회이면 호흡단락수는 11 개가 된다. 전 
체 음절수가 210 개이므로 이를 호흡단락수로 나누어 호흡단락 당 음절수를 구하였다.

69 개의 전체 어절 중 어절과 어절 사이의 경계, 즉 어절경계 에서 휴지가 동반된 어절의 비율을 구하였다. 이는 휴지횟수를 전체어절수로 나눈 백분율로 계산하였다. 어절경계는 어절 사 이(어절간)에 위치하므로 여기서 사용한 휴지횟수는 어절간 휴 지횟수만 포함하였다. 예를 들어 흡기 동반 어절간 휴지가 9회, 흡기 미동반 어절간 휴지가 1 회였다면 전체 어절간 휴지횟수는 10 회가 된다. 이를 전체어절수인 69로 나누면 이 참여자의 휴지 동반 어절 비율은 $14.5 \%$ 가 된다.

\subsection{2. 신뢰도 분석}

흡기 동반 및 미동반 휴지 선정의 평가자간 신뢰도를 구하기 위해 음성장애 환자의 평가 및 중재경력이 20 년 이상인 전문가 1 인이 전체 참여자 수의 $20 \%$ 에 해당하는 16 명의 자료로 어절간 및 어절내, 흡기 동반 및 미동반 휴지를 구분하도록 하였다. 이 를 본 연구자의 결과와 Pearson 적률상관분석을 통해 비교한 결 과 신뢰도는 $99.75 \%$ 로 매우 높게 나타났다.

\subsection{3. 통계 분석}

정상군 및 환자군 측정치의 집단내 및 집단간 측정치의 기술 및 추론통계 분석은 SPSS(ver 24.0) for Windows 프로그램을 이 용하여 시행하였다. 기술통계로는 각 측정치의 평균 및 표준편 차를 구하였다. 각 측정치의 집단간 차이의 유의성은 독립표본 $t$-검정을 이용하였고 측정치 간의 상관 정도는 Pearson 적률상 관분석을 이용하여 분석하였다.

\section{3. 연구결과}

정상성대를 가진 성인 여성 40 명으로 구성된 정상군과 기능 적 음성장애를 진단받은 성인 여성 40 명으로 구성된 환자군을 대상으로 문단낭독 시 공기역학적 검사결과를 근거로 휴지와 호흡단락에 대해 분석하였다.

3.1. 정상군 및 환자군의 휴지 및 호흡단락 분석결과 정상군 및 환자군의 문단낭독 시 흡기 동반 및 미동반, 어절 간 및 어절내 휴지에 대해 분석한 결과를 표 2에 제시하였다.
표 2. 정상군 및 환자군의 문단낭독 시 휴지 및 호흡단락 분석 결과 Table 2. Results of pauses and breath groups during paragraph reading for normal and patient groups

\begin{tabular}{|c|c|c|c|c|}
\hline $\begin{array}{l}\text { 측정항목 } \\
\text { (단위) }\end{array}$ & 집단 & 평균 & $\begin{array}{l}\text { 표준 } \\
\text { 편차 }\end{array}$ & $t$-value \\
\hline \multirow{2}{*}{ 흡기 동반 어절간 휴지(회) } & 정상군 & 10.15 & 2.93 & \multirow{2}{*}{$-2.645^{* *}$} \\
\hline & 환자군 & 12.05 & 3.47 & \\
\hline \multirow{2}{*}{ 흡기 미동반 어절간 휴지(회) } & 정상군 & 1.18 & 1.22 & \multirow{2}{*}{1.112} \\
\hline & 환자군 & 0.90 & 0.98 & \\
\hline \multirow{2}{*}{ 흡기 동반 어절내 휴지(회) } & 정상군 & 0.00 & 0.00 & \multirow{2}{*}{ - } \\
\hline & 환자군 & 0.00 & 0.00 & \\
\hline \multirow{2}{*}{ 흡기 미동반 어절내 휴지(회) } & 정상군 & 0.23 & 0.48 & \multirow{2}{*}{0.483} \\
\hline & 환자군 & 0.18 & 0.45 & \\
\hline \multirow{2}{*}{ 호흡단락수(개) } & 정상군 & 11.15 & 2.93 & \multirow{2}{*}{$-2.645^{* *}$} \\
\hline & 환자군 & 13.05 & 3.47 & \\
\hline
\end{tabular}

어절간 휴지 중 흡기 동반의 경우 정상군은 평균 10.15 회, 환 자군은 평균 12.05 회로 환자군이 유의하게 더 많은 휴지를 보였 다 $(t=-2.645, p<.05)$. 흡기를 동반하지 않은 경우의 어절간 휴지 는 정상군 1.18 회, 환자군 0.90 회로 흡기를 동반했을 때와는 달 리 환자군이 더 적은 휴지를 보였으나 그 차이는 유의하지 않았다.

어절내 휴지 중 흡기를 동반한 경우는 정상군, 환자군 총 80 명이 모두 0 의 수치를 보였다. 흡기를 동반하지 않은 경우 정상 군은 40 명 중 8 명이 1 회(7명) 혹은 2 회(1명)의 어절내 휴지를 보 인 것으로 나타났고 환자군은 40 명 중 7명이 1회(6회) 혹은 2 회 (1회)의 어절내 휴지를 보인 것으로 나타났다. 이를 통해 어절내 휴지는 어절간 휴지보다 현저히 적은 수로 나타났고 그 차이도 유의하지 않았음을 알 수 있었다.

호흡단락수는 흡기가 일어난 횟수에서 1 을 더한 수로 계산하 였는데 분석결과 흡기는 흡기 동반 어절간 휴지와 같은 장소에 서 나타났다. 결국 모든 호흡단락수는 흡기 동반 어절간 휴지 횟수에서 1 을 더한 것과 같은 수치를 보였다. 그래서 정상군은 11.15 개, 환자군 13.05 개로 나타나 흡기 동반 어절간 휴지와 마 찬가지로 환자군이 정상군보다 유의하게 높았다 $(t=-2.645$, $p<.05)$.

3.2. 정상군 및 환자군의 휴지 동반 어절 비율과 호흡단락당 음절수 분석결과

정상군 및 환자군의 문단낭독 시 휴지 동반 어절경계 비율(전 체 어절경계 중 어절간 휴지를 동반하는 경우의 비율)과 호흡단 락당 음절수(한 호흡단락에 포함된 평균 음절수)에 대해 분석한 결과는 표 3 과 같다. 
표 3. 정상군 및 환자군의 문단낭독 시 휴지 동반 어절경계 비율과 호흡단락당 음절수 분석 결과

Table 3. Results of syntactic words boundary rate with pause and number of syllables per breath group during paragraph reading for normal and patient groups

\begin{tabular}{c|c|c|c|c}
\hline $\begin{array}{c}\text { 측정항목 } \\
\text { (단위) }\end{array}$ & 집단 & 평균 & $\begin{array}{c}\text { 표준 } \\
\text { 편차 }\end{array}$ & $t$-value \\
\hline \multirow{2}{*}{ 휴지 동반 어절경 계 비율 $(\%)$} & 정상군 & 16.40 & 4.90 & \multirow{2}{*}{$-2.062^{*}$} \\
\cline { 2 - 5 } & 환자군 & 18.80 & 5.30 & \\
\hline \multirow{2}{*}{ 호흡단락당 음절수(개) } & 정상군 & 20.13 & 5.32 & \multirow{2}{*}{$2.546^{* *}$} \\
\cline { 2 - 5 } & 환자군 & 17.24 & 4.64 & \\
\hline \multirow{2}{*}{$*$}
\end{tabular}

문단낭독 시 휴지 동반 어절경계 비율은 정상군이 $16.4 \%$, 환 자군이 $18.8 \%$ 로 환자군의 휴지 동반 비율이 정상군보다 유의하 게 높았다 $(t=-2.062, p<.05)$. 그리고 호흡단락당 음절수는 정상 군은 20.13 개, 환자군은 17.24 개로 정상군의 음절수가 환자군보 다 유의하게 많았다 $(t=2.546, p<.01)$.

\section{3. 측정치 간의 상관성 분석결과}

흡기 동반 및 미동반 어절간 휴지횟수, 흡기 미동반 어절내 휴지횟수, 휴지 동반 어절경계 비율과 호흡단락당 음절수 측정 치 간의 상관정도를 알아보기 위해 Pearson 상관분석을 실시한 결과를 표 4에 제시하였다(흡기 동반 어절내 휴지는 모든 참여 자가 0 의 횟수를 보였기 때문에 계산이 불가하여 제외하였다).

표 4. 측정치 간의 상관성 분석 결과

Table 4. Correlation analysis results among measurements

\begin{tabular}{c|c|c|c|c|c}
\hline & 1 & 2 & 3 & 4 & 5 \\
\hline 1 & 1 & & & & \\
\hline 2 & .081 & 1 & & & \\
\hline 3 & .003 & .010 & 1 & & \\
\hline 4 & $.952^{* *}$ & $.383^{* *}$ & .006 & 1 & \\
\hline 5 & $-.944^{* *}$ & -.083 & -.050 & $-.901^{* *}$ & 1 \\
\hline${ }^{* *} p<.01$.
\end{tabular}

1 , 흡기 동반 어절간 휴지횟수; 2 , 흡기 미동반 어절간 휴지횟 수; 3 , 흡기 미동반 어절내 휴지횟수; 4 , 휴지 동반 어절경계 비 율; 5 , 호흡단락당 음절수.

위의 표에서 보는 것처럼 유의한 상관을 보인 것은 전체 25 개 비교쌍 중 4개였다. 흡기 동반 어절간 휴지와 휴지 동반 어절경 계 비율 $(r=.952)$, 흡기 동반 어절간 휴지와 호흡단락당 음절수 $(r=-944)$, 휴지 동반 어절경계 비율과 호흡단락당 음절수 $(r=$ -.901)은 .90 이상의 높은 상관을 보였다. 흡기 미동반 어절간 휴 지와 휴지 동반 어절경계 비율의 상관성은 유의하기는 했으나 .38 의 낮은 상관을 보였다. 이 4 개를 제외한 21 개 쌍은 .10 이하 의 매우 낮은 상관을 보였다.

\section{4. 논의 및 결론}

본 연구에서는 정상성대를 가진 성인 여성 40 명으로 구성된 정상군과 기능적 음성장애를 진단받은 성인 여성 40 명으로 구
성된 환자군을 대상으로 문단 낭독 시 휴지와 호흡단락에 대해 분석하였다. 그 결과 흡기를 동반한 어절간 휴지횟수와 호흡단 락수는 환자군이 정상군보다 유의하게 높았다. 흡기를 동반하 지 않은 어절간 및 어절내 휴지는 비록 유의하지는 않았어도 정 상군이 환자군보다 더 높았다. 전체 어절경계 중 휴지를 동반한 어절경계 비율은 환자군이 정상군보다 유의하게 더 높게 나타 났으나 호흡단락당 음절수는 정상군이 유의하게 더 높았다. 측 정치 간의 상관성을 분석한 결과 흡기 동반 어절간 휴지와 휴지 동반 어절경계 비율, 흡기 동반 어절간 휴지와 호흡단락당 음절 수, 휴지 동반 어절경계 비율과 호흡단락당 음절수는 .90 이상 의 높은 상관을 보였다.

흡기를 동반한 어절간 휴지의 횟수는 환자군이 정상군보다 유의하게 더 높았다(12.05회와 10.15회). 음성장애를 동반한 화 자는 호흡기나 호흡근의 문제를 동반하지는 않으나 성대폐쇄 의 비정상성을 동반한다(Gartner-Schmidt et al., 2015). 발화 시 성대의 폐쇄가 불완전하게 이루어지면 성문 틈새로 기류가 낭 비되면서 상대적으로 발화를 지속할 수 있는 호흡지지의 시간 을 단축시킨다. 이로 인해 정상군보다 더 많은 수의 흡기가 필 요했을 것으로 판단된다. 이는 발화 시 호흡지지의 문제를 동반 하는 다른 의사소통장애 화자의 발화에서도 나타난다. Hong \& Byeon(2014)은 이완형 마비말장애 화자 15 명과 정상화자 15 명 의 쉼 특성을 비교한 결과 환자군의 전체 쉼의 빈도가 정상군보 다 더 높게 나타났다고 보고하였다. 연구자들은 이완형 마비말 장애 화자는 종종 호흡의 문제를 동반하며 이러한 불충분한 호 흡이 한숨에 발화할 수 있는 길이를 짧게 하는 것으로 설명하였다.

음성장애 화자의 성대폐쇄부전으로 인한 호흡지지의 문제는 호흡단락당 음절수가 환자군(17.24개)보다 정상군(20.13개)에 서 더 높게 나타난 것과 상관이 깊다. 즉 정상군은 환자군보다 호흡지지를 더 길게 지속할 수 있으므로 한 호흡단락 시 산출할 수 있는 음절수가 환자군보다 평균적으로 5개 음절 이상을 더 지속할 수 있었다. 휴지 동반 어절경계 비율이 환자군이 더 높 은 것, 다시 말하면 정상군이 더 적은 어절경계에서 흡기를 동 반한 휴지를 보인 것도 같은 맥락에서 판단할 수 있다.

두 군의 참여자 모두 흡기 동반 어절내 휴지는 보이지 않았 다. 흡기를 동반하지 않은 어절내 휴지도 두 군 모두 평균 0.2 회 안팎(정상군 0.23 회, 환자군 0.18 회)의 매우 낮은 빈도를 보였다. Wang et al.(2010)은 호흡단락은 주로 문법규칙에 따라 나타난 다고 하였다. 본 연구에 참여한 음성장애 화자는 음성 문제 외 의 다른 의사소통 문제를 동반하고 있지 않으므로 문법규칙 등 언어에 대한 지식은 문제가 없었다. 그러므로 어절경계가 아닌 곳에서 휴지를 보이는 경우는 거의 없었다. 정상 화자도 일상 대화 시에는 문법규칙에 맞지 않는 곳에서 휴지를 보이기도 하 므로(Wang et al., 2010) 일상대화라면 이 비율이 더 높았을 수 있다. 그러나 본 연구에서는 문단을 낭독하도록 하여 발화 내용 을 화자가 머릿속에서 구상해야 할 필요가 없었고 검사 전 문단 내용을 한 번 묵독하도록 했으므로 어절경계가 아닌 곳에서 나 타나는 휴지는 두 군 모두 매우 적게 나타났다.

정상군의 호흡단락당 음절수가 평균 20.13 개인 것은 Han et 
al.(2008)이 호흡그룹당 평균 음절수가 17.95 개로 측정되었다고 보고한 데 비하면 매우 높은 수치이다. 이는 사용한 낭독자료와 문단낭독 길이의 차이에 기인한다고 볼 수 있다. Han et al.(2008) 은 본 연구에서 사용한 ‘가을' 문단이 아니라 ‘산책' 문단(Jeong, 1993, as cited in Han et al, 2008)을 사용하여 문단을 구성하는 언 어적 구성(음소, 음절구조 등)이 달랐다. 또한 이 연구는 음절수 가 아니라 시간을 기준으로 낭독을 종료하도록 했다. 즉 60 초 동안 문단을 읽도록 했기 때문에 산출된 음절수가 223개에서 341 개로 다양하기 때문에 210 음절을 기준으로 낭독을 종료하 도록 한 본 연구결과와 직접 비교하기 어려운 면이 있다.

환자군의 호흡단락당 음절수가 17.24개로 보고된 것은 Pyo et al.(2014)의 연구에 참여한 음성장애 환자군 중 48세 이전 환자 군의 15.69 개에 비하면 역시 높은 수치이다. 이들은 본 연구와 같은 낭독자료를 사용하여 발화자료의 차이는 없으나 연구 참 여자의 차이가 결과의 차이를 유발한 것으로 보인다. 본 연구에 참여한 환자군은 성대결절, 성대용종, 만성 후두염 등 기능적 음성장애를 진단받은 환자들이었으나 Pyo et al.(2014)에 참여한 음성장애 환자는 성대양성병변 환자를 대상으로 했으므로 성 대결절이나 성대용종뿐 아니라 성대낭종 환자도 포함되어있었 다. 성대낭종은 만성 후두염에 비하면 성대폐쇄부전의 정도가 더 심각하므로 이로 인해 이들의 연구에서 평균 음절수가 더 적 게 나타났을 것으로 판단된다.

흡기를 동반한 어절간 및 어절내 휴지와 달리 흡기를 동반하 지 않은 어절간 혹은 어절내 휴지의 평균 횟수는 비록 그 차이 가 유의하지는 않았으나 정상군이 환자군보다 약간 더 높았다. 정상군은 호흡지지가 충분하여 흡기 없이도 휴지를 둘 수 있지 만 환자군은 상대적으로 호흡지지가 약하므로 흡기가 없는 휴 지보다 흡기를 동반한 휴지가 발화유지에 더 유리하다. 이러한 양상이 측정결과에 영향을 미쳤을 것으로 보인다.

각 측정치 간의 상관성을 분석한 결과 가장 높은 상관정도를 보인 것은 흡기 동반 어절간 휴지와 휴지 동반 어절경계 비율 $(r=.952)$ 이었다. 어절경계는 어절 사이에서 나타나므로 이 위치 에서 흡기가 나타난 비율을 보여주는 휴지 동반 어절경계 비율 은 상관성이 높게 나타날 수밖에 없다. 그 다음으로 높은 상관 성을 보인 것은 흡기 동반 어절간 휴지와 호흡단락당 음절수로 -.944의 부적상관을 보였다. 이는 흡기 동반 어절간 휴지가 많 아질수록 호흡단락당 음절수는 감소한다는 의미인데 흡기 동 반 어절간 휴지가 많아진다는 것은 흡기횟수가 많아짐을 의미 하고 이는 다시 호흡단락의 수가 증가함을 의미한다. 동일한 음 절수를 가진 상황에서 호흡단락의 수가 높아지면 호흡단락에 포함되는 음절수는 적어지게 된다.

연구결과를 통해 음성장애 화자는 정상화자에 비해 더 많은 흡기 동반 휴지와 더 많은 호흡단락수를 보이는 것으로 나타났 다. 이는 성대폐쇄부전으로 인해 호흡지지가 부족하여 나타나 는 현상으로 판단할 수 있는데 잦은 흡기의 동반은 발화의 흐름 을 저해한다. 그러므로 음성장애 화자를 평가할 때 부적절한 휴 지 혹은 빈번한 휴지를 보이지 않는지 확인할 필요가 있고 이러 한 문제가 발견되었을 때에는 호흡지지 훈련을 통해 불필요하
게 잦은 휴지 및 흡기의 빈도를 감소시켜야 한다.

본 연구는 문단낭독 시 휴지와 호흡단락을 구분하는 데 공기 역학적 분석방법을 활용하였다. Wang et al.(2010)은 흡기의 궤 적은 공기역학적 방법을 통한 기류량의 변화를 파악함으로써 쉽게 구분할 수 있다고 했다. 본 연구도 이러한 방법을 활용하 여 휴지 및 호흡단락에 대해 보다 더 객관적인 근거로 분석했다 는 데에서 의의를 찾을 수 있다.

본 연구는 문단낭독 시 휴지와 호흡단락의 특성을 공기역학 적 검사를 통해 분석하였으므로 이 결과를 일상 대화 상황으로 일반화시키기는 어렵다. 일상대화와 문단낭독은 같은 사람이 산출했다고 해도 발화속도가 다르고 휴지를 두는 방법이 다르 다. Wang et al.(2012)은 문단낭독에 비해 일상 자발화는 호흡단 락이 더 길고 흡기를 동반한 휴지가 문법적으로 적절하지 않은 데에도 나타난다고 보고하였다. Hodge \& Rochet(1989)도 일상 대화와 낭독의 호흡단락당 음절수를 비교한 결과 낭독 시 그 음 절수가 더 높게 나타났다고 했다. Yoo \& Shin(2019)은 청, 장년 층 정상성인 남녀가 낭독 및 자유발화를 산출했을 때 휴지 특성 을 분석하여 낭독 발화보다 자유발화의 휴지가 더 길다고 하였 다. 그러므로 추후에 음성장애 화자의 일상대화 시 휴지는 문단 낭독 시 휴지와 비교해 어떤 차이를 보이는지 알아보는 연구가 이루어져야 한다.

본 연구에 참여한 음성장애 화자는 기능적 음성장애를 동반 한 화자들이었다. 이들은 음성 오남용을 주원인으로 하기 때문 에 대개 성대의 과내전(hyperadduction)을 동반하는 경우가 많 다. 이들이 보이는 성대폐쇄부전은 대개 성대에 생긴 혹이나 부 기가 폐쇄를 방해하기 때문에 나타난다. 그러므로 성대마비 (vocal fold paralysis)나 성대구증(sulcus vocalis) 등 성대 내전력 이 부족하여 성대폐쇄부전이 나타나는 경우는 기능적 음성장 애 환자와 또 다른 양상을 보일 수 있으므로 본 연구결과를 적 용하는 데 무리가 있다. 성대과소기능 환자의 휴지 및 호흡단락 에 대한 연구는 국내에서는 거의 이루어진 바가 없으므로 이에 대한 추후연구도 지속되어야 한다.

\section{References}

Choi, H. (2001). Oral reading rate and features of pauses of profoundly hearing-impaired and normally hearing children at school age (Master's thesis). Ewha Womans University, Seoul, Korea.

Gartner-Schmidt, J. L., Hirai, R., Dastolfo, C., Rosen, C. A., Yu, L., \& Gillespie, A. I. (2015). Phonatory aerodynamics in connected speech. Laryngoscope, 125(12), 2764-2771.

Han, J., Lee, O., \& Shim, L. (2008). The study of breath group based on oral airflow in reading by healthy speakers. Speech Sciences, 15(4), 135-146.

Hodge, M. M., \& Rochet, A. P. (1989). Characteristics of speech breathing in young women. Journal of Speech and Hearing Research, 32(3), 466-480. 
Hong, S., \& Byeon, H. (2014). Speech rate and pause characteristics in speaker with flaccid dysarthria. Journal of the Korea AcademiaIndustrial Cooperation Society, 15(5), 2930-2936.

Huber, J. E., Darling, M., Francis, E. J., \& Zhang, D. (2012). Impact of typical aging and Parkinson's disease on the relationship among breath pausing, syntax, and production. American Journal of SpeechLanguage Pathology, 21(4), 368-379.

Kim, H. (2005). Neurogenic speech and language disorders. In H. Sim, Y. Kim, J. Kim, H. Kim, S. Bae, M. Shin, S. Lee, ... J. Han (Eds.), Introduction to communicative disorders (pp. 149-178). Seoul, Korea: Hakjisa.

Kim, Y. (2002). Assessment and treatment of language disorders in children. Seoul, Korea: Hakjisa.

Ko, Y., Kim, D. Y., Choi, Y., \& Kim, H. H. (2010). Speech rate and pause characteristics in patients with Parkinson's disease. Phonetics and Speech Sciences, 2(4), 173-184.

Lee, H., \& Kim, S. J. (2017). Comparison of overall speaking rate and pause between children with speech sound disorders and typically developing children. Phonetics and Speech Sciences, 9(2), 111-118.

Lee, S., Ko, H., \& Kim, S. J. (2007). Prosody of cerebral palsic adults' speech. Proceedings of the 2007 Fall Conference of the KSPS (pp. 49-51).

Pyo, H., Kim, S., \& Baek, S. (2014). A comparison study of breath groups during reading paragraph tasks in normal adults and adult patients with voice disorders: A preliminary study. Phonetics and Speech Sciences, 6(4), 181-187.

Wang, Y. T., Green, J. R., Nip, I. S., Kent, R. D., Kent, J. F., \& Ullman, C. (2010). Accuracy of perceptually based and acoustically based inspiratory loci in reading. Behavior Research Methods, 42(3), 791-797.

Wang, Y. T., Nip, I. S., Green, J. R., Kent, R. D., Kent, J. F., \& Ullman, C. (2012). Accuracy of perceptual and acoustic methods for the detection of inspiratory loci in spontaneous speech. Behavior Research Methods, 44(4), 1121-1128.

Winkworth, A. L., Davis, P. J., Ellis, E., \& Adams, R. D. (1994). Variability and consistency in speech breathing during reading: Lung volumes, speech intensity, and linguistic factors. Journal of Speech, and Hearing Research, 37(3), 535-556.

Yoo, D., \& Shin, J. (2019). A realization of pauses in utterance across speech style, gender, and generation. Phonetics and Speech Sciences, 11(2), 33-44.

- 표화영 (Hwa Young Pyo) 교신저자

조선대학교 언어치료학과 교수

광주시 필문대로 309

Tel: 062-230-6188

Email: entvoice@chosun.ac.kr 


\title{
정상성인 여성 화자와 음성장애 성인 여성 화자의 문단 낭독 시 휴지 및 호흡단락 특성의 비교
}

\author{
표 화 영
}

조선대학교 언어치료학과

\begin{abstract}
국문초록
본 연구는 정상군과 음성장애 환자군의 문단낭독 시 휴지 및 호흡단락 특성을 파악해보고자 시행되었다. 정상군 40명과 기능적 음성장애 환자군 40명을 대상으로 PAS(Phonatory Aerodynamic System) 중 Running Speech를 이용하 여 ‘가을' 문단을 낭독하게 하였다. 이를 통해 흡기 동반 및 미동반, 어절간 및 어절내 휴지와 호흡단락을 구분하고 이에 대한 기술통계 및 집단간 통계적 유의성을 검증하였다. 그 결과 흡기를 동반한 휴지횟수는 환자군이 더 높았 으나 흡기를 동반하지 않은 휴지횟수는 정상군이 더 높은 수치를 보였다. 어절경계 중 휴지가 동반된 비율은 환자 군이 더 높았고 호흡단락당 음절수는 정상군이 유의하게 더 높았다. 음성장애 화자군은 성대폐쇄부전으로 인한 호 흡지지가 정상군보다 부족하므로 휴지 시 흡기를 동반하는 경우나 호흡단락의 수가 더 많은 것으로 사료된다. 이 는 일상대화의 자연스러움을 저해할 수 있으므로 음성장애 화자의 중재 시 휴지와 호흡단락의 빈도를 적절히 조절 하는 것도 평가 및 중재에 포함해야 할 것이다.
\end{abstract}

핵심어: 음성장애 환자, 공기역학적 분석, 휴지, 호흡단락

\section{참고문헌}

고열매, 김덕용, 최예린, 김향희(2010). 파킨슨 병 환자의 말속도 와 쉼 특성. 말소리와 음성과학, 2(4), 173-184.

김영태(2002). 아동언어장애의 진단 및 치료. 서울: 학지사.

김향희(2005). 신경 말-언어장애. In 이승환, 배소영, 심현섭, 김영

태, 김향희, 신문자, 한재순, ... 김진숙(편). 의사소통장애의 이 해(pp.149-178). 서울: 학지사.

유도영, 신지영(2019). 과제, 성별, 세대에 따른 휴지의 실현양상 연구. 말소리와 음성과학, 11(2), 33-44.

이숙향, 고현주, 김수진(2007). 뇌성마비 성인 발화의 운율 특징. 한국음성과학회 2007 가을학술대회 발표논문집, 49-51.

이흥임, 김수진(2017). 말소리장애 아동과 일반아동의 발화속도 와 쉼 비교. 말소리와 음성과학, $9(2), 111-118$.

최현주(2001). 심도 청각장애아동과 정상아동의 소리내어 읽기 속도와 심 특성 비교. 이화여자대학교 석사학위논문.

표화영, 김소연, 백승국(2014). 정상 성인 화자와 음성장애 성인 화자의 문단낭독 시 호흡단락에 대한 비교연구: 예비연구. 말
소리와 음성과학, 6(4), 181-187.

한지연, 이옥분, 심이슬(2008). 구강기류 분석에 근거한 정상 성 인의 문단 읽기 시 호흡그룹의 특징. 음성과학, 15(4), 135-146. 홍새미, 변해원(2014). 이완형 마비말장애 화자의 말속도와 쉼 특 성. 한국산학기술학회 논문지, 15(5), 2930-2936. 